\title{
S-SHAPED TRANSITION CURVES AS AN ELEMENT OF REVERSE CURVES IN ROAD DESIGN
}

\author{
ANDRZEJ KOBRYŃ* ${ }^{*}$ PIOTR STACHERA \\ Dept of Energy Efficient Construction and Geodesy, \\ Faculty of Civil Engineering and Environmental Sciences, \\ Bialystok University of Technology, Bialystok, Poland
}

Received 26 December 2018; accepted 15 May 2019

\begin{abstract}
A road designing involves horizontal and vertical alignment. The horizontal geometry is formed by straight and curvilinear sections that are traditionally formed using circular and transition curves (mainly the clothoid). Different geometric systems that are designed using circular and transition curves are between others circular curves with symmetrical or unsymmetrical clothoids, combined curves, oval curves and reverse curves. Designing these systems is quite complex. Therefore, so-called $S$-shaped transition curves are an alternative to traditional approaches. These curves are known from literature and are modern geometric tools for the shaping of reverse curves. The paper analyses the basic geometric properties of these curves as well as compare to the geometry of the appropriate geometric systems, which are formed with clothoid or using $S$-shaped transition curves. In addition, a procedure for designing reverse curves using $S$-shaped transition curves was proposed. Another research topic was the comparison of the analysed reverse curves (created using polynomial transition curves) with traditional curves (created using the clothoid). The results of the
\end{abstract}

* Corresponding author. E-mail: a.kobryn@pb.edu.pl

Andrzej KOBRYŃ (ORCID ID 0000-0002-4775-8164)

Piotr STACHERA (ORCID ID 0000-0001-9717-5234)

Copyright (C) 2019 The Author(s). Published by RTU Press

This is an Open Access article distributed under the terms of the Creative Commons Attribution License (http://creativecommons.org/licenses/by/4.0/), which permits unrestricted use,

distribution, and reproduction in any medium, provided the original author and source are credited. 
studies, despite the noticeable differences in the geometry of the compared components, confirm the practical usefulness of the $S$-shaped transition curves for designing the geometry of the route.

Keywords: reverse curves, road geometry, $S$-shaped transition curves.

\section{Introduction}

The determining of horizontal alignment plays a key role in road design. The horizontal alignment is usually set using straight lines, circular curves ad transition curves. The most popular transition curve is the spiral curve (also known as the clothoid), whose curvature changes linearly with the increase of the length, making it very easy to shape the curvature (Brockenbrough, 2009). Apart from the spiral curve, other curves are also included. Such a possibility is permitted by the existing regulations (Ministra Transportu i Gospodarki Morskiej, 1999) and road design guidelines (Generalna Dyrekcja Dróg Publicznych, 1995a, 1995b, 1995c). Between various curves that potentially expand the range of design tools used for the geometric design of roads, so-called polynomial transition curves deserve special attention. These curves provide a flexible tool to facilitate the geometric alignment of routes to terrain constraints. Various curves of this type have been presented in the works (Grabowski, 1984; Kobryń, 2016a, 2017a). In works (Kobryń, 2016a, 2017a), it is proposed to divide the polynomial transition curves into several categories:

- classical transition curves,

- quasi-transition curves,

- general transition curves,

- $S$-shaped transition curves,

- oval transition curves,

- universal transition curves.

The categories as mentioned above of transition curves have excellent application potential and are useful in the design of curvilinear sections of road routes, both in the situational plan and in the longitudinal profile. The subjects of the current research are various aspects of application nature. As a result, for example, Kobryń (2017b) describes the appropriate proposals and methodology for dealing with the use of polynomial transition curves in the classical sense. In turn, Kobryn (2016b) presents a methodology and various aspects of using these transition curves for the design of vertical curves.

As is known (American Association of State..., 2018; Brockenbrough, 2009; Easa, 2003; Garber \& Hoel, 2014; Kühn, 2013; Lamm, Psarianos, \& Mailaender, 1999; Rogers \& Enright, 2016; Wolhuter, 2015), 
different geometric systems are used in the horizontal alignment, e.g. compound, reverse and combined curves. Traditionally shaping this type of geometry requires generally tedious design works, which involve the need for a smooth connecting of several geometric elements (circular arcs and transition curves). The advantage of polynomial transition curves is the description of the entire curvilinear transition between two straight lines using only one equation. Therefore, in the opinion of authors, the use of an appropriate category of polynomial transition curves are a noteworthy alternative to the traditional approach.

Analysis of shaping the geometry of reverse curves will be considered in this article. Such problems were analysed in literature relatively rarely. Generally, reverse curves formed by two clothoids are described in handbooks. Other curves that have been analysed as elements of reverse curves are circular arcs (Easa, 1994) or quantic polynomials (Shebl, 2015). Authors of these papers express the opinion that reverse curves give the possibility of shaping the using so-called $S$-shaped transition curves that have been presented in Kobryń $(2016 a, 2017 a)$ works. These curves are the subject of further discussion in this article.

\section{Analysed solutions of S-shaped transition curves}

Polynomial solutions of $S$-shaped transition curves have been defined by Kobryń (2016a, 2017a) as curves whose curvature varies continuously from zero at the starting point $P$ to zero at the endpoint $K$. Within these curves, there is one inflexion point $S$ (where the value of the curvature is also zero). The inflexion point divides the $S$-shaped transition curve into two parts, each with one extreme of curvature (Figure 1). Various solutions of polynomial transition curves, presented in Kobryń (2016a, 2017a) works, are based on the appropriate polynomial function in general form:

$$
y=f(x)=\sum_{i=0}^{i=n} a_{i} x^{i}
$$

Appropriate boundary conditions (presented in Kobryń (2016a, 2017a) works) for the values of this function and its derivativesy $y^{\prime}, y^{\prime \prime}$ and $y^{\prime \prime \prime}$ at points, $P$ and $K$ are taken into account in the function (1). Consideration of these conditions is required to define the desired distribution of curvature within the curve. In agreement to Kobryń (2016a, 2017a), appropriate Equations for two families of $S$-shaped transition curves result from Eq. (1) for $n=5$ and $n=7$. 
In agreement to Kobryń (2016a, 2017a), the Eq. (1) of the $S$-shaped of Reverse Curves transition curves that were obtained using Eq. (1) for $n=5$, has the in Road Design following form

$$
y=x_{K}\left(M_{0} \tan \alpha+M_{1} \tan u_{P}+M_{2} \tan u_{K}\right),
$$

where

$$
\begin{aligned}
& M_{0}=10 t^{3}-15 t^{4}+6 t^{5} \\
& M_{1}=t-6 t^{3}+8 t^{4}-3 t^{5} \\
& M_{2}=-4 t^{3}+7 t^{4}-3 t^{5}
\end{aligned}
$$

and in agreement to Figure 1: $x_{K}$ - abscissa of the endpoint $K$ in the local coordinates system; $\alpha$ - angle of chord inclination connecting points $P$ and $K ; u_{P}, u_{K}-$ angles of tangent inclination respectively at points $P$ and $K$.

The variable $x$ in Eq. (2) is replaced by the variable $t=\frac{x}{x_{K}}$ with the values $t \in 0 ; 1$. As a result, the abscissa $x_{K}$ of the point $K$ plays the role of a size, which scales the curve (the design parameter, which determines the span of the curve). Other designing parameters for these curves are values $\tan \alpha, \tan u_{P}$, and $\tan u_{K}$.

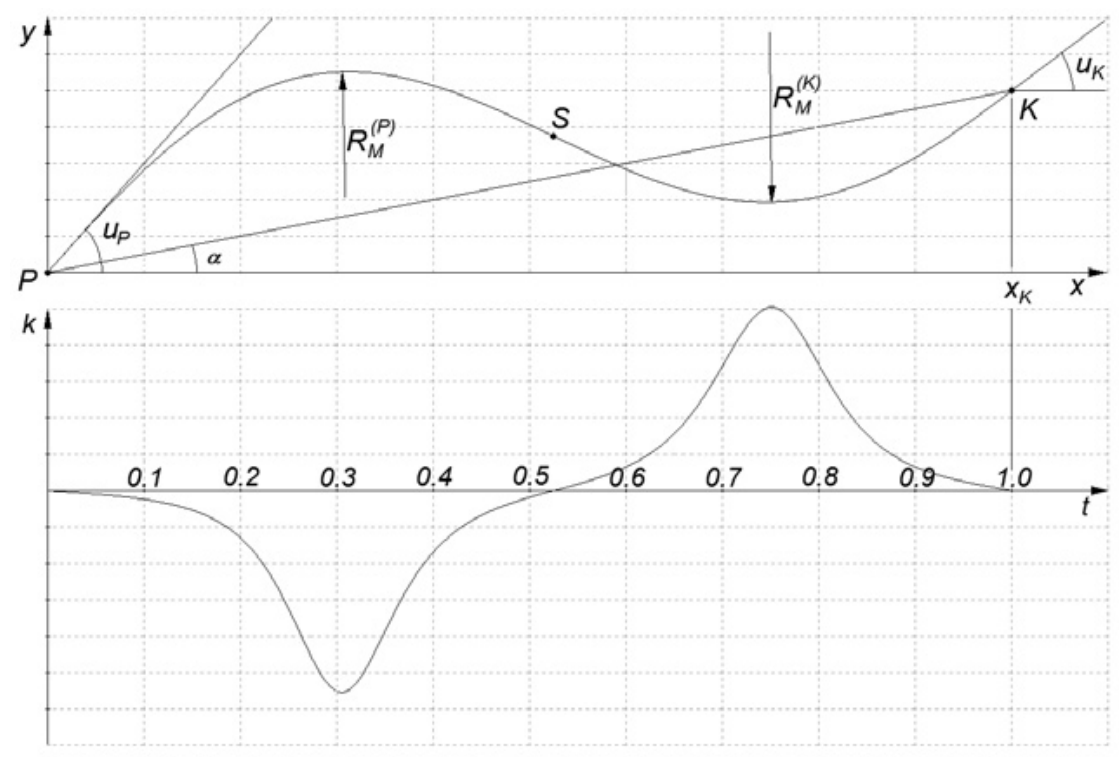

Figure 1. S-shaped transition curves and graph of her curvature (Kobryń, 2016a) 
In the case of the solution (2), obtaining of the curvature distribution, which is appropriate for $S$-shaped transition curves, requires to meet of following conditions (in agreement to Kobryń (2017a)):

$$
\begin{gathered}
\tan u_{P} \cdot \tan u_{K}>0, \\
\tan \alpha=M_{1 / 0}^{(I I)} \tan u_{P}+M_{2 / 0}^{(I I)} \tan u_{K} .
\end{gathered}
$$

The coefficients $M_{1 / 0}^{(\mathrm{II})}$ and $M_{2 / 0}^{(\mathrm{II})}$ in Eq. (4) are the result of the graphs of the functions $M_{1 / 0}^{(\mathrm{II})}(t)=-\frac{M_{1}^{\prime \prime}}{M_{0}^{\prime \prime}}$ and $M_{2 / 0}^{(\mathrm{II})}(t)=-\frac{M_{2}^{\prime \prime}}{M_{0}^{\prime \prime}}$. Values of these coefficients from the allowable intervals $\left(M_{1 / 0}^{(\mathrm{II})} \in \frac{2}{5} ; \frac{3}{5}\right.$ and $\left.M_{2 / 0}^{(\mathrm{II})} \in \frac{2}{5} ; \frac{3}{5}\right)$ allow obtaining a correct distribution of curvature within the curve (Kobryń, 2011).

The second equation of $S$-shaped transition curves obtained on the basis Eq. (1) for $n=7$ has the following form:

$$
y=x_{K}\left(G_{0} \tan \alpha+G_{1} \tan u_{P}+G_{2} \tan u_{K}\right),
$$

where

$$
\begin{gathered}
G_{0}=34 t^{4}-84 t^{5}+70 t^{6}-20 t^{7}, \\
G_{1}=t-20 t^{4}+45 t^{5}-36 t^{6}+10 t^{7}, \\
G_{2}=-15 t^{4}+39 t^{5}-34 t^{6}+10 t^{7} .
\end{gathered}
$$

The meaning of symbols, which were used in Eq. (5) is analogous to Eq. (2).

As in the case of curves (2), it is necessary to meet the appropriate conditions to obtain the curvature distribution suitable for $S$-shaped transition curves. The first condition is analogous to (3), while the second condition is the equivalent of condition (4) that has the form (in agreement to Kobryń (2017a)):

$$
\tan \alpha=G_{1 / 0}^{(\mathrm{II})} \tan u_{P}+G_{2 / 0}^{(\mathrm{II})} \tan u_{K} .
$$

The coefficients $G_{1 / 0}^{(\mathrm{II})}$ and $G_{2 / 0}^{(\mathrm{II})}$ in Eq. (6) are the result of the graphs of the functions $G_{1 / 0}^{(\mathrm{II})}(t)=-\frac{G_{1}^{\prime \prime}}{G_{0}^{\prime \prime}}$ and $G_{2 / 0}^{(\mathrm{II})}(t)=-\frac{G_{2}^{\prime \prime}}{G_{0}^{\prime \prime}}$. 
Values of these coefficients from the allowable intervals of Reverse Curves $\left(G_{1 / 0}^{(\mathrm{II})} \in \frac{3}{7} ; \frac{4}{7}\right.$ and $\left.G_{2 / 0}^{(\mathrm{II})} \in \frac{3}{7} ; \frac{4}{7}\right)$ allow obtaining a correct distribution of curvature within the curve (Kobryń, 2011).

In practical applications related to the layout of reverse curves, it is justified to write Equations of curves (2) and (5) in a more straightforward form that is possible after adopting $\tan \alpha=0$ (Figure 2). The Eq. (2) takes the form:

$$
y=x_{K}\left(M_{1} \tan u_{P}+M_{2} \tan u_{K}\right) .
$$

In turn, the Eq. (5) takes the form

$$
y=x_{K}\left(G_{1} \tan u_{P}+G_{2} \tan u_{K}\right) .
$$

In light of design conditions, it is essential below the permissible values of curvature. Due to the strictly defined distribution of curvature, controlling this condition requires determining the position and value of the curvature extremes that for any function $y=f(x)$ is described by Eq. (9):

$$
k=\frac{\left|y^{\prime \prime}\right|}{\left(1+y^{\prime 2}\right)^{\frac{3}{2}}} .
$$

The position of the curvature extremes that is determined by the value of the variable $t=t_{M}=\frac{x_{M}}{x_{K}}\left(x_{M}-\right.$ abscissa of the extreme point, $x_{K}$ - abscissa of the endpoint), results from the solution of a nonlinear equation in the form (in agreement to Kobryń (2016a)):

$$
y^{\prime \prime \prime}\left(1+y^{\prime 2}\right)-3 y^{\prime} y^{\prime \prime 2}=0,
$$

where $y^{\prime}, y^{\prime \prime}$ and $y^{\prime \prime \prime}$ are derivatives of the corresponding function (2) or (5).

Then, the radius of curvature corresponding to the value $t_{M}$ is calculated based on Eq. (8). It is described by following Equations (11) and (12), in agreement to Kobryń (2016a)):

- for curves (7)

$$
R_{M}=x_{K} \frac{\left[1+\left\{M_{1}^{\prime \prime \prime}\left(t_{M}\right) \tan u_{P}+M_{2}^{\prime \prime \prime}\left(t_{M}\right) \tan u_{K}\right\}^{2}\right]^{\frac{3}{2}}}{\left|M_{1}^{\prime \prime \prime}\left(t_{M}\right) \tan u_{P}+M_{2}^{\prime \prime \prime}\left(t_{M}\right) \tan u_{K}\right|} ;
$$




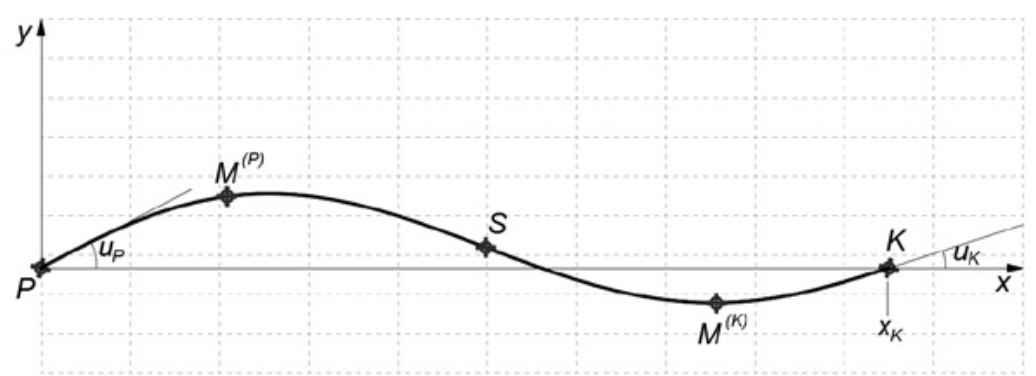

Note: $M(P), M(K)$ - points of maximum curvature in the first and second section of the curve.

Figure 2. S-shaped transition curves for $\tan \alpha=0$.

- for curves (8)

$$
R_{M}=x_{K} \frac{\left[1+\left\{G_{1}^{\prime \prime \prime}\left(t_{M}\right) \tan u_{P}+G_{2}^{\prime \prime \prime}\left(t_{M}\right) \tan u_{K}\right\}^{2}\right]^{\frac{3}{2}}}{\left|G_{1}^{\prime \prime \prime}\left(t_{M}\right) \tan u_{P}+G_{2}^{\prime \prime \prime}\left(t_{M}\right) \tan u_{K}\right|} .
$$

\section{Basic geometric characteristics of the S-shaped transition curves}

Taking into account the Eq. (9), follows that the condition of the existence of extremes of curvature (Eq. (10)) is replaced - with some simplification - by a necessary condition in the form $y^{\prime \prime \prime}=0$. This condition results from the fact that $\left|y^{\prime \prime}\left(t_{M}\right)\right| \geq\left|y^{\prime \prime}(t)\right| \geq|k(t)|$. The necessary condition $y^{\prime \prime \prime}=0$ has the form:

- for curves (7)

$$
\frac{\tan u_{P}}{\tan u_{K}}=-\frac{-24+84 t^{2}-60 t^{3}}{-36+96 t^{2}-60 t^{3}}
$$

- for curves (8)

$$
\frac{\tan u_{P}}{\tan u_{K}}=-\frac{-360 t+2340 t^{2}-4080 t^{3}+2100 t^{4}}{-480 t+962700 t^{2}-4320 t^{3}+2100 t^{4}} .
$$

In turn, the necessary condition of the existence of the inflexion point $\left(y^{\prime \prime}=0\right)$ has the form (in agreement to Kobryń (2016a)): 
- for curves (7)

$$
\frac{\tan u_{P}}{\tan u_{K}}=-\frac{-24 t+28 t^{3}-15 t^{4}}{-36 t+32 t^{3}-15 t^{4}}
$$

- for curves (8)

$$
\frac{\tan u_{P}}{\tan u_{K}}=-\frac{-180 t^{2}+780 t^{3}-1020 t^{4}+420 t^{5}}{-240 t^{2}+900 t^{3}-1080 t^{4}+420 t^{5}} .
$$

Values $t_{S}, t_{E}^{(1)}$ and $t_{E}^{(2)}$ those describe the position of the inflexion point $S$ and the position of extremes of the derivative $y^{\prime \prime}$ for selected values of the ratio $\frac{\tan u_{P}}{\tan u_{K}}$ are summarised in Table 1.

The value of the ratio $\frac{\tan u_{P}}{\tan u_{K}}$ has an impact on the position of the inflexion point $S$ and points of the extreme derivative $y^{\prime \prime}$ :

- in the case of equal inclination values, the inflexion point lies in the middle of the curve length $\left(t_{S}=0.5\right)$;

- for $\frac{\tan u_{P}}{\tan u_{K}}>1$, the inflexion point lies closer to the end of the curve;

- for $\frac{\tan u_{P}}{\tan u_{K}}<1$, the inflexion point lies closer to the beginning of the curve;

- values $t_{E}$ that describes the location of extreme points increase with increasing of the ratio $\frac{\tan u_{P}}{\tan u_{K}}$.

Additionally, detailed calculations (not quoted here) were made for various values of tangent inclinations in the range $1^{\circ} ; 89^{\circ}$. Based on these calculations, it was found that the inflexion point $S$ in the case of curves (7) assumes a position in the range $t_{S} \in \frac{2}{5} ; \frac{3}{5}$, whereas in the case of curves (8) - in the range $t_{S} \in \frac{3}{7} ; \frac{4}{7}$. It has also been found that points with maximum curvature values assume a position in the range:

- $t_{M}^{(1)} \in 0.09 ; 0.33$ and $t_{M}^{(2)} \in 0.67 ; 0.91$ for curves (7);

- $t_{M}^{(1)} \in 0.13 ; 0.33$ and $t_{M}^{(2)} \in 0.67 ; 0.87$ for curves (8). 
Table 1. Values of variable $t$ describing the location of a curve inflexion point and extremes of derivative $y^{\prime \prime}$

\begin{tabular}{ccccccc}
\hline Ratio & \multicolumn{5}{c}{ Curves (7) } & \multicolumn{3}{c}{ Curves (8) } \\
\cline { 2 - 7 } $\tan u_{P}$ & $t_{S}$ & $t_{E}^{(1)}$ & $t_{F}^{(2)}$ & $t_{S}$ & $t_{E}^{(1)}$ & $t_{F}^{(2)}$ \\
\hline $\tan u_{K}$ & & & & & \\
\hline 0.1 & 0.4182 & 0.1828 & 0.7627 & 0.4416 & 0.2518 & 0.7014 \\
0.2 & 0.4333 & 0.1882 & 0.7673 & 0.4524 & 0.2565 & 0.7053 \\
0.3 & 0.4462 & 0.1928 & 0.7713 & 0.4615 & 0.2605 & 0.7088 \\
0.4 & 0.4571 & 0.1967 & 0.7747 & 0.4694 & 0.2638 & 0.7117 \\
0.5 & 0.4667 & 0.2000 & 0.7778 & 0.4762 & 0.2667 & 0.7143 \\
0.6 & 0.4750 & 0.2029 & 0.7805 & 0.4821 & 0.2691 & 0.7166 \\
0.7 & 0.4824 & 0.2054 & 0.7829 & 0.4874 & 0.2713 & 0.7186 \\
0.8 & 0.4889 & 0.2076 & 0.7850 & 0.4921 & 0.2732 & 0.7205 \\
0.9 & 0.4947 & 0.2096 & 0.7869 & 0.4962 & 0.2749 & 0.7221 \\
1.0 & 0.5000 & 0.2113 & 0.7887 & 0.5000 & 0.2764 & 0.7236 \\
2.0 & 0.5333 & 0.2222 & 0.8000 & 0.5238 & 0.2857 & 0.7333 \\
3.0 & 0.5500 & 0.2275 & 0.8058 & 0.5357 & 0.2902 & 0.7383 \\
4.0 & 0.5600 & 0.2306 & 0.8094 & 0.5429 & 0.2929 & 0.7414 \\
5.0 & 0.5667 & 0.2327 & 0.8118 & 0.5476 & 0.2946 & 0.7435 \\
6.0 & 0.5714 & 0.2342 & 0.8135 & 0.5510 & 0.2959 & 0.7449 \\
7.0 & 0.5750 & 0.2352 & 0.8148 & 0.5536 & 0.2968 & 0.7461 \\
8.0 & 0.5778 & 0.2361 & 0.8158 & 0.5556 & 0.2975 & 0.7469 \\
9.0 & 0.5800 & 0.2368 & 0.8166 & 0.5571 & 0.2981 & 0.7476 \\
10.0 & 0.5818 & 0.2373 & 0.8172 & 0.5584 & 0.2986 & 0.7482 \\
\hline & & & & & & \\
\hline
\end{tabular}

Some specific geometric properties of these curves are relevant considering the usefulness of the $S$-shaped transition curves for forming the reverse curves. Namely, with the increase of inclinations $\tan u_{P}$ and $\tan u_{K}$, there are relatively longer sections with a small curvature (bolded in Figure 3) in the vicinity of points $P, K$ and $S$.

It is, therefore, necessary to determine the maximum values of tangent inclinations $\left(\tan u_{P}\right.$ and $\left.\tan u_{K}\right)$ at points $P$ and $K$, where changes of curvature in those sections of the curve do not exceed certain limit values that were resulting from standard guidelines, e.g. Generalna Dyrekcja Dróg Publicznych (1995a, 1995b, 1995c). As a reference curve, the spiral curve is used. Its Equation has the form (Kobryń, 2017a):

$$
k=\frac{1}{r}=\frac{1}{R} t,
$$


where $t=\frac{l}{L} ; l$ - natural parameter; $L$ - total length of the spiral curve; of Reverse Curves $R$ - designed minimum radius of the curvature at the point $K$, which is in Road Design for $t=1$.

For example, will be compared the radius of curvature at two points, whose position is described by values $t$ and $+\Delta t$, respectively. Assuming $\Delta t=0.05$ is obtained:

$$
\begin{aligned}
& \text { - } \frac{r_{t}}{r_{t+\Delta t}}=2.0 \text { for } t=0.05 \\
& \text { - } \frac{r_{t}}{r_{t+\Delta t}}=1.5 \text { for } t=0.10 \\
& \text { - } \quad \ldots ; \\
& \text { - } \frac{r_{t}}{r_{t+\Delta t}}=1.0526315 \text { for } t=0.095 .
\end{aligned}
$$

It follows that the most significant changes of the radius are in the initial part of the spiral transition curve. These changes are below $\frac{r_{t}}{r_{t+\Delta t}}=2.0$. Therefore, it is justified by the analysis to take into account $\frac{r_{t}}{r_{t+\Delta t}} \leq 2.0$ also for these critical sections of $S$-shaped transition curves.

Due to the multitude of different combinations of values $\tan u_{P}$ and $\tan u_{K}$, it is possible to include here the results of calculations only for some possible values $\tan u_{P}$ and $\tan u_{K}$. The authors of this article carried out a wide range of studies of this type of studies. Selected values

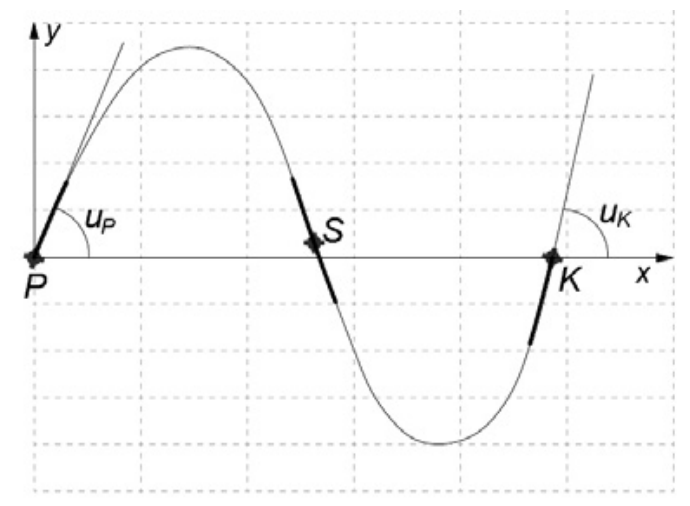

Figure 3. Sections of the S-shaped transition curve with minimal values of curvature 
Table 2. Values $\tan u_{P}$ and $\tan u_{K}$ for those

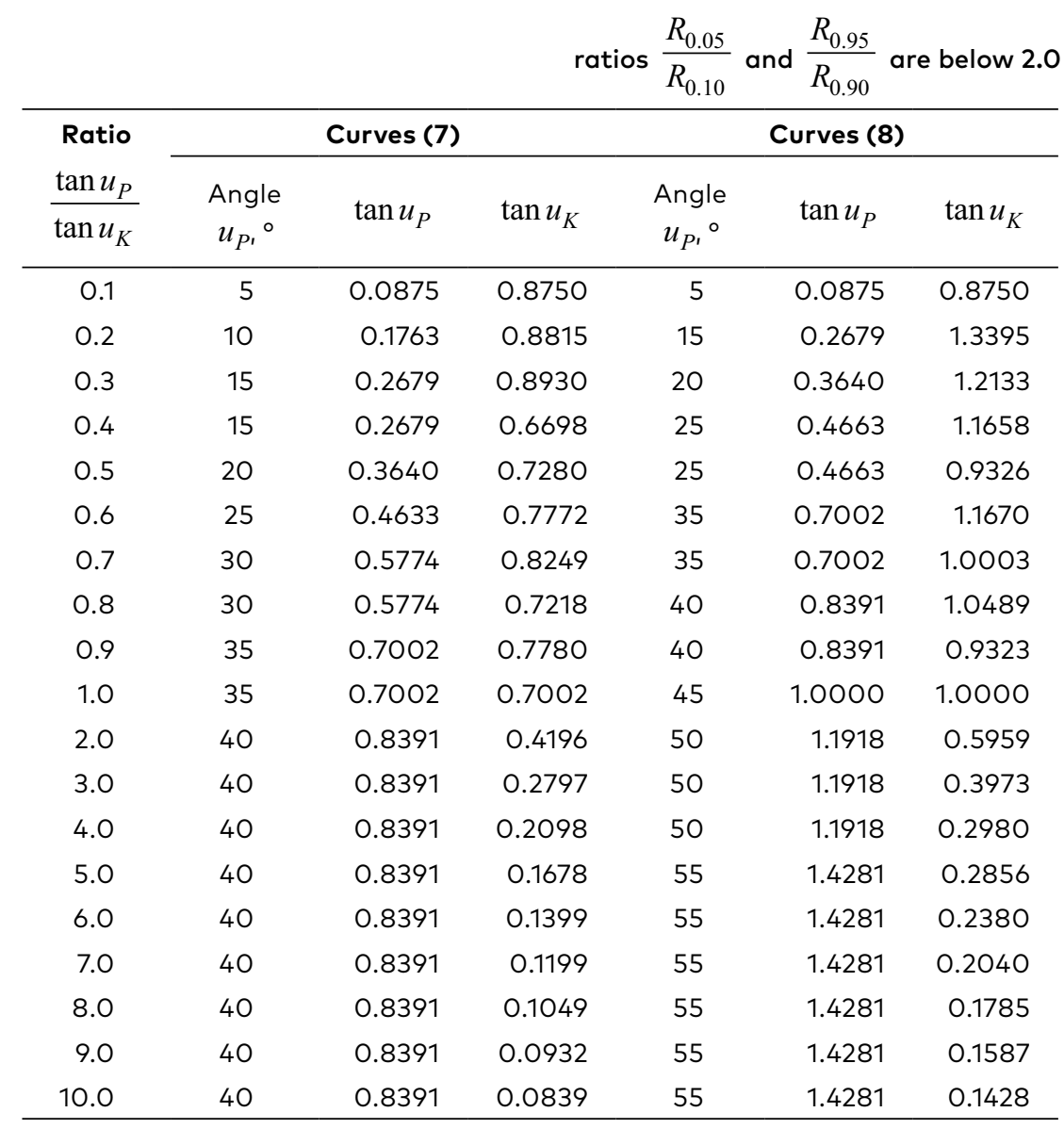

resulting from these calculations are summarised in Table 2. Presented results are illustrative. Therefore, they were here limited to the vicinity of points of $P$ and $K$, omitting results regarding neighbourhood of the inflexion point $S$.

In the light of presented values, it is reasonable to use in the designing practice of curves (7) and (8) under certain conditions:

- in the case of curves (7) - if angles of tangent inclinations are below $40^{\circ}$;

- in the case of curves (8) - if angles of tangent inclinations are below $55^{\circ}$.

It is possible, that - in design practice - it is necessary to have, for example, appropriate nomograms that allow rapid evaluation of the fulfilment of the above requirements by $S$-shaped transition curves. 


\section{Designing of reverse curves using $S$-shaped transition curves}

In practical applications, which are associated with laying out of reverse curves using $S$-shaped transition curves, generally there are two design options:

- $1^{\text {st }}$ option - a connecting of two points $P\left(X_{P}, Y_{P}\right)$ and $K\left(X_{K}, Y_{K}\right)$ with a given position in the superordinate coordinates system (in that a whole route is designed) as well with given tangent directions at $P$ and $K$ (Figure 4$)$;

- $\quad 2^{\text {nd }}$ option - a positioning of points $P^{\prime}$ and $K^{\prime}$ on tangents with given directions in such a way as not to exceed permissibly, i.e. resulting from proper guidelines, values of curvature within the curve (Figure 5).

In addition - regardless of the above design options - it is important that the parameter of the transition $\left(A^{2}=R L\right)$ meets certain conditions that are defined in the relevant regulations.

In agreement to Figures 4 and 5, the curvilinear transition created by the $S$-shaped transition curves in both options will be designed in the local coordinate system of these curves $(x y)$. A defining this transition in connection with the entire route is possible by appropriate coordinate transformation to the superordinated coordinate system.

In the first option, the starting point is a calculation of values $\tan u_{P}$ and $\tan u_{K}$ (in the local coordinate system as in Figure 4) based on present positions of points $P$ and $K$ and given tangent directions in these points. Then, based on the Eq. (10), values $t_{M}$ are calculated. These values

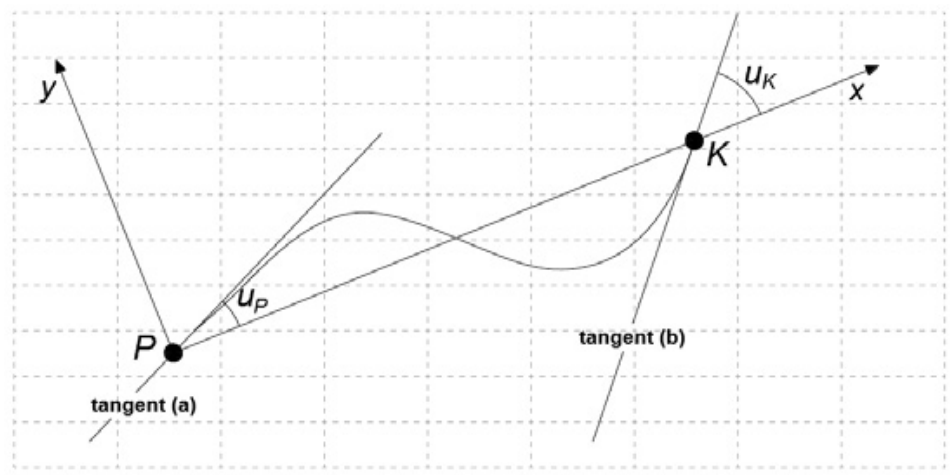

Figure 4. The first option: S-shaped transition curve connecting given points $P$ and $K$ 


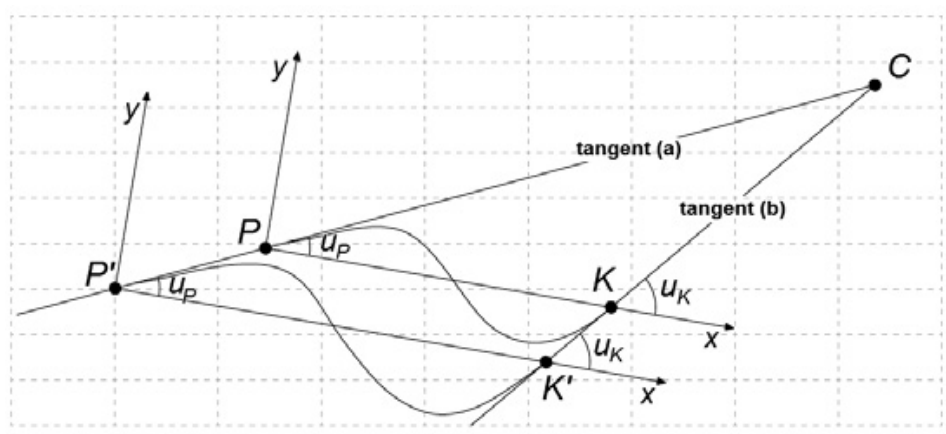

Figure 5. The second option: S-shaped transition curve connecting given points $P$ and $K$

describe the position of curvature extremes in the first and second sections of the curve (Figure 2). The next step is to check that the radii of curvature at points $M^{(P)}$ and $M^{(K)}$ do not exceed permissible values. However, it is to be expected that the radii calculated based on Eqs (11) or (12) would exceed the limit values. In this case, correction of positions of the start and endpoint of the curve will be required in agreement to a procedure described below.

In the second option, it is essential to determine if a minimum value of the abscissa $x_{K}$ of the point $K$ In the local coordinates system of the $S$-shaped transition curve. It is important to ensure that the permissible (i.e. resulting from suitable guidelines) values of curvature at points $M^{(P)}$ and $M^{(K)}$ are not exceeded. As in the first option, the values of inclination $\tan u_{P}$ sand $\tan u_{K}$ must be calculated first based on positions of points $P$ and $K$ and tangent directions given in these points. Subsequently, the position of points $M^{(P)}$ and $M^{(K)}$ must be determined based on Eq.(10) (values $t_{M}=t_{M}^{(P)}$ and $t_{M}=t_{M}^{(K)}$ determine the position). The next step is to calculate the abscissa length $x_{K}$, that corresponds to values $t_{M}=t_{M}^{(P)}$ and $t_{M}=t_{M}^{(K)}$, tangent inclinations $\tan u_{P}$ and $\tan u_{K}$ and the designed minimum radius $R_{M}$. As it follows from Eqs (11) and (12), the abscissa $X_{K}$ is calculated as:

- for curves (7)

$$
x_{K}=R_{M} \frac{\left|M_{1}^{\prime \prime \prime}\left(t_{M}\right) \tan u_{P}+M_{2}^{\prime \prime \prime}\left(t_{M}\right) \tan u_{K}\right|}{\left[1+\left\{M_{1}^{\prime \prime \prime}\left(t_{M}\right) \tan u_{P}+M_{2}^{\prime \prime \prime}\left(t_{M}\right) \tan u_{K}\right\}^{2}\right]^{\frac{3}{2}}},
$$


- for curves (8)

$$
x_{K}=R_{M} \frac{\left|G_{1}^{\prime \prime \prime}\left(t_{M}\right) \tan u_{P}+G_{2}^{\prime \prime \prime}\left(t_{M}\right) \tan u_{K}\right|}{\left[1+\left\{G_{1}^{\prime \prime \prime}\left(t_{M}\right) \tan u_{P}+G_{2}^{\prime \prime \prime}\left(t_{M}\right) \tan u_{K}\right\}^{2}\right]^{\frac{3}{2}}} .
$$

Additionally, a distance between points $P\left(X_{P}, Y_{P}\right)$ and $K\left(X_{K}, Y_{K}\right)$ in the super-ordinated coordinates system is calculated:

$$
d_{P K}=\sqrt{\left(X_{K}-X_{P}\right)^{2}+\left(Y_{K}-Y_{P}\right)^{2}}
$$

If $d_{P K} \geq x_{K}$, it means that no point of the $S$-shaped transition curve will exceed the permissible value of the curvature, i.e. value resulting from proper guidelines. Otherwise, points $P$ and $K$ on tangents are determined so that their connection using the $S$-shaped transition curve with the permissible values of curvature will be obtained.

Based on Figure 5, it is stated that the abscissa of the point $C$ in the local coordinates system (defined by points $P$ and $K$ ) will be expressed as:

$$
x_{C}=d_{P K} \frac{\tan u_{K}}{\tan u_{K}-\tan u_{P}} .
$$

From the above follows the ordinate $y_{C}=x_{C} \tan u_{P}$ as well as the distance between points $P$ and $C$ that is equal to $d_{P C}=\sqrt{x_{C}^{2}+y_{C}^{2}}$. Based on Figure 5, it follows:

$$
d_{P^{\prime} C}=\frac{x_{K}}{d_{P K}} d_{P C}
$$

As a result, taking into account $d_{P^{\prime} P}=d_{P^{\prime} C}-d_{P C}$, coordinates of the point $P^{\prime}$ in the local coordinates system defined by points $P$ and $K$ will be expressed as:

$$
\begin{aligned}
& x_{P^{\prime}}=x_{P}-d_{P^{\prime} P} \cos u_{p}, x_{P^{\prime}}=x_{P}-d_{P^{\prime} P} \sin u_{p}, \text { if } \tan u_{P}<\tan u_{K} ; \\
& x_{P^{\prime}}=x_{P}+d_{P^{\prime} P} \cos u_{p}, x_{P^{\prime}}=x_{P}+d_{P^{\prime} P} \sin u_{p}, \text { if } \tan u_{P}<\tan u_{K} .
\end{aligned}
$$

Further steps regarding connecting of points $P$ and $K$ using $S$-shaped transition curve (7) or (8) are related to the use of the Equations given in the end part of Section 2. It is necessary to calculate appropriate radii of curvature and control whether they do not exceed values resulting from proper guidelines. 


\section{Geometry comparison of traditional and proposed reverse curves}

A comparison of the geometry of traditional curves with curves formed by $S$-shaped transition curves is very valuable. Therefore, traditional curves formed by two fragments of curves in the form of two clothoids sequence, also known as a vertex clothoid, was adopted as a reference (Figure 6).

Corresponding calculations to compare the curves formed by symmetric, reverse and vertex clothoids with curves in the form of $S$-shaped transition curves were made. These calculations were done in three variants of assumptions abort values of angles $\alpha_{1}$ and $\alpha_{2}$ :

- variant I: $\alpha_{1}=52^{\circ}, \alpha_{2}=41^{\circ}$;

- variant II: $\alpha_{1}=26^{\circ}, \alpha_{2}=20^{\circ}$;

- variant III: $\alpha_{1}=104^{\circ}, \alpha_{2}=82^{\circ}$.

Using known formulas (Brockenbrough, 2009; Wolhuter, 2015), for the above angles and the given distance between points $B$ and $C$ $\left(d_{B C}=730.81 \mathrm{~m}\right)$, fundamental values for curves formed by symmetric vertex clothoids were first determined:

- variant I: $\tau_{1}=26^{\circ}, \tau_{2}=20.5^{\circ}$, the parameter $\alpha=389.169$;

- variant II: $\tau_{1}=13^{\circ}, \tau_{2}=10^{\circ}$, the parameter $\alpha=572.045$;

- variant III: $\tau_{1}=52^{\circ}, \tau_{2}=41^{\circ}$, the parameter $\alpha=235.102$.

As a result, other geometric sizes were also calculated, describing the symmetrical curves of two vertex clothoids. In this way, it was possible to determine the position of points $P$ and $K$ that were assumed as footing points also for the main chord of the $S$-shaped transition curve (7) and (8).

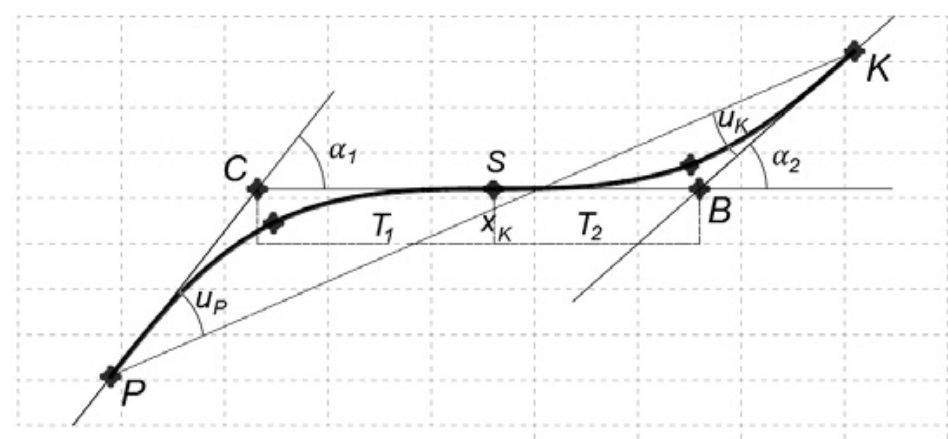

Figure 6. Baseline assumptions for comparing traditional and proposed reverse curves 


\begin{tabular}{|c|c|c|c|c|c|c|c|}
\hline Variant & $\begin{array}{l}\text { Curve } \\
\text { type }\end{array}$ & $t_{S}$ & $t_{M}^{(1)^{*}}$ & $R_{1}, \mathrm{~m}$ & $t_{M}^{(2)_{\star}}$ & $R_{2}, \mathrm{~m}$ & $L, \mathrm{~m}$ \\
\hline I & $\begin{array}{c}\text { vertex } \\
\text { clothoids }\end{array}$ & 0.5247 & 0.2628 & 408.36 & 0.7621 & 458.92 & 1401.79 \\
\hline \multirow{2}{*}{$x_{K}=1338.08$} & curve (7) & 0.5251 & 0.2393 & 508.16 & 0.7962 & 589.25 & 1393.30 \\
\hline & curve (8) & 0.5179 & 0.2838 & 382.81 & 0.7430 & 454.83 & 1417.32 \\
\hline \multirow{3}{*}{$x_{K}=1430.78$} & $\begin{array}{c}\text { vertex } \\
\text { clothoids }\end{array}$ & 0.5314 & 0.2647 & 848.73 & 0.7650 & 967.93 & 1447.27 \\
\hline & curve (7) & 0.5270 & 0.2267 & 1125.60 & 0.7977 & 1348.65 & 1444.26 \\
\hline & curve (8) & 0.5193 & 0.2843 & 865.35 & 0.7352 & 1032.30 & 1450.28 \\
\hline \multirow{3}{*}{$x_{K}=985.27$} & $\begin{array}{c}\text { vertex } \\
\text { clothoids }\end{array}$ & 0.5068 & 0.2367 & 174.45 & 0.7409 & 196.49 & 1196.06 \\
\hline & curve (7) & 0.5375 & 0.2723 & 138.21 & 0.8095 & 172.04 & 1243.41 \\
\hline & curve (8) & 0.5268 & 0.2937 & 102.95 & 0.7714 & 137.18 & 1338.57 \\
\hline
\end{tabular}

Note: *in the case of vertex clothoids, this is the size referring to the length of entire curve connecting points $P$ and $t=\frac{1}{L}$, analogous as for curves (7) and (8).

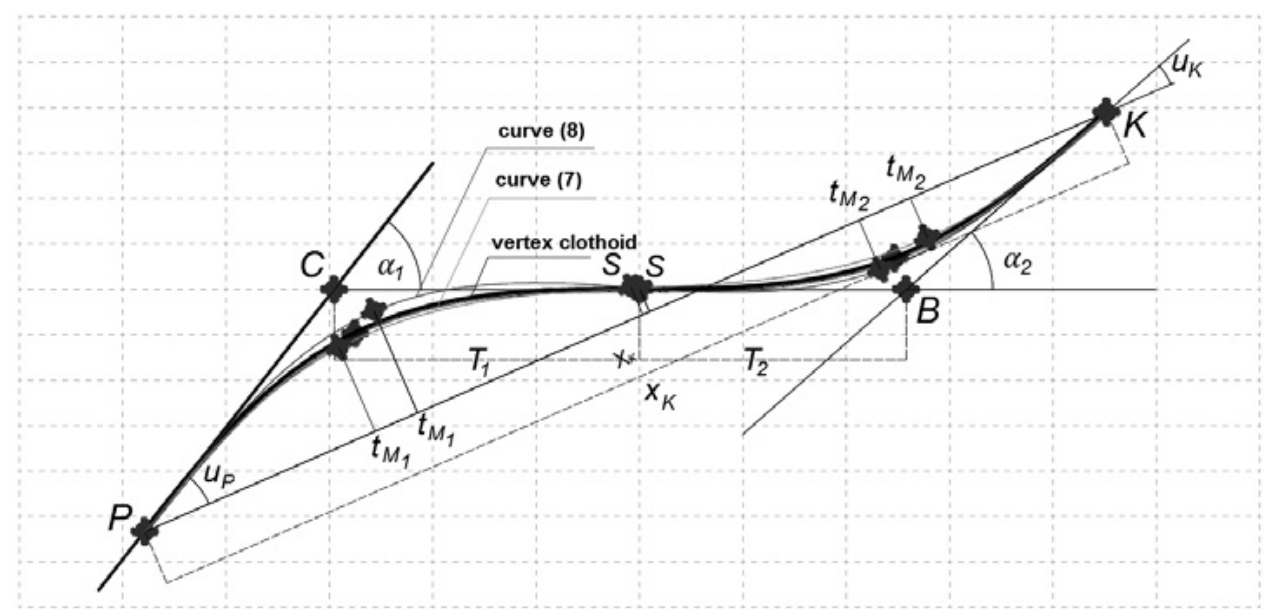

Figure 7. Reverse curves: symmetric vertex clothoids vs S-shaped transition curves (variant I) 


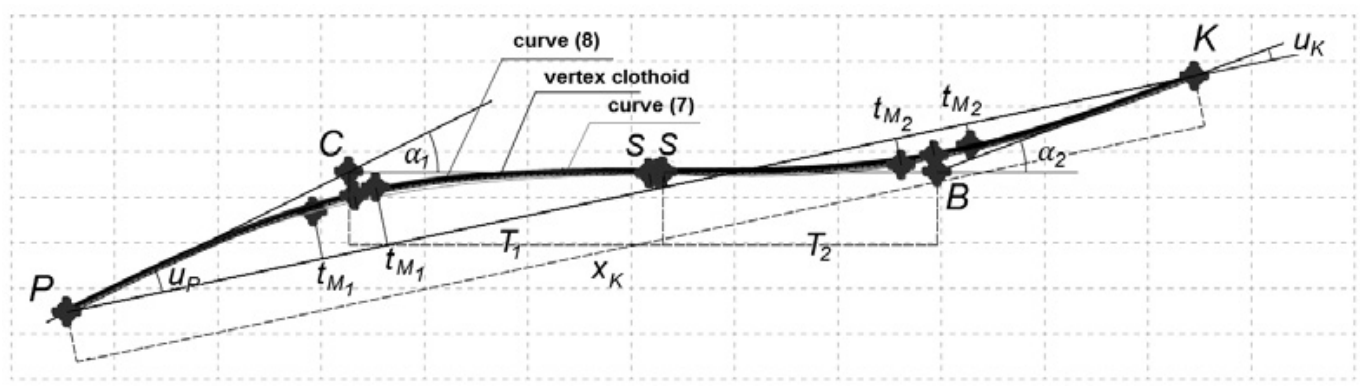

Figure 8. Reverse curves: symmetric vertex clothoids vs S-shaped transition curves (variant II)

Then, using the Equations given in Section 2, the geometrical sizes of curves formed by curves (7) and (8) were calculated. Besides, lengths of curves connecting points $P$ and $K$, formed by both vertex clothoids and $S$-shaped transition curves (7) and (8), were calculated. Obtained values were summarised in Table 3.

Additionally, Figures 7-9 show a typical illustration of curves formed by vertex clothoids and curves in the form of $S$-shaped transition curves

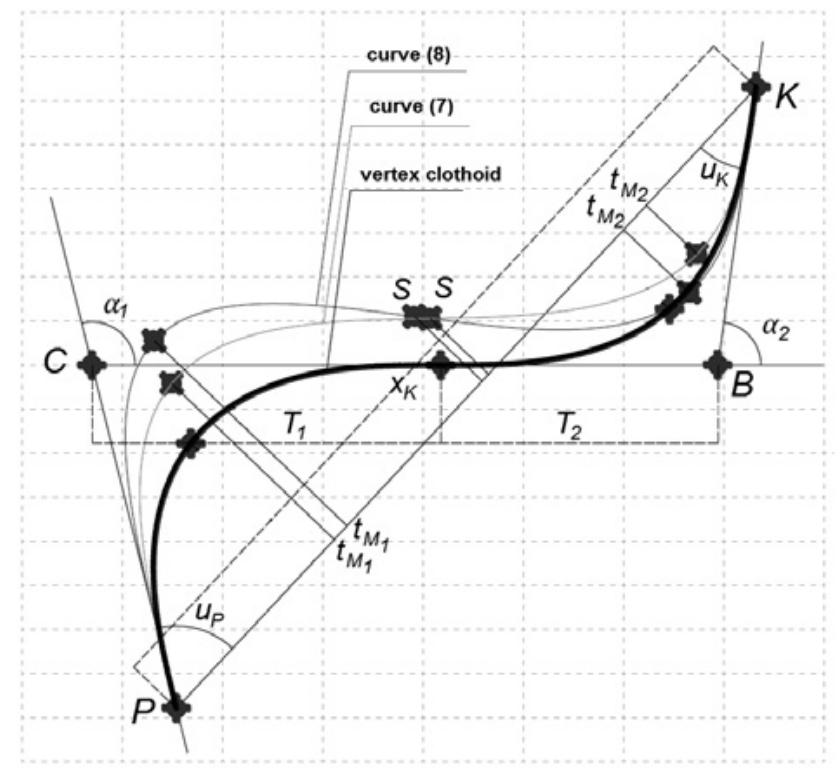

Figure 9. Reverse curves: symmetric vertex clothoids vs S-shaped transition curves (variant III) 
(7) and (8). From Table 6 and Figures 7-9 follows that, in the case of tangent inclinations, $S$-shaped transition curves allow obtaining larger radii in points with the maximum curvature. Additionally, the increase in tangent inclination results in noticeable elongation of curves formed by $S$-shaped transition curves relative to the length of the traditional curves, as well as the greater deviation of these curves relative to the curves formed by vertex clothoids.

\section{Conclusions}

1. This article presents alternative geometric tools in the form of so-called $S$-shaped transition curves that are useful for the routing of reverse curves. An essential feature of these curves compared to traditional highway curves (formed by the sequence of spiral curves) is that they allow a description of the entire curvilinear transition between two points using only one equation. The proposed solutions are useful in horizontal alignment wherever appropriate regulations provide the use of curvilinear transitions.

2. The analyses allowed to determine limit values of angles of tangent inclinations, for whose $S$-shaped transition curves are useful in practical applications in the routing of reverse curves. These angles are no more than $40^{\circ}$ for the first family of considered curves and no more than $55^{\circ}$ for the second family of curves. When using higher values of tangent inclinations, the geometry of these curves becomes inadequate from design practice. Within the curves, there are too long sections with relatively small changes in curvature. For this reason, the above restrictions on the values of tangent inclinations are a specific drawback of the proposed curves.

3. The article also presents the method of forming of reverse curves using $S$-shaped transition curves so that the permissible, i.e. resulting from proper guidelines, values of curvature are not exceeded. The proposed methodology has an algorithmic character, so it is suitable for possible implementation in appropriate computer software for road design.

4. The article also contains examples to compare a geometry of curves in the form of two vertex clothoids with corresponding curves formed using $S$-shaped transition curves. These examples have shown that, for smaller angles of tangent inclinations, the 
geometry of traditional and proposed curves is very similar. This feature of the proposed solutions is important in light of design practice. Therefore, $S$-shaped transition curves are an alternative to traditional ways of forming reverse curves. It should be noted that these curves describe the whole curvilinear transition between two points using only one equation.

5. Whereas, for larger angles of tangent inclinations, greater deviations of $S$-shaped transition curves relative to traditional curves are observed. It is a desirable feature of $S$-shaped transition curves. As a result, in the case of possible terrain restrictions, a designer has more different types of geometric tools that give wider possibilities to an adjustment of a route to these restrictions.

\section{REFERENCES}

American Association of State Highway and Transportation Officials (AASHTO) (2018). A policy on geometric design of highways and streets, 7th edition, Washington, DC.

Brockenbrough, R. L. (Ed.), (2009). Highway engineering handbook. 3rd edition, McGraw-Hill, Professional Book Group, New York.

Easa, S. M. (2003). Geometric design. The civil engineering handbook. CRC Press, Taylor \& Francis Group, Boca Raton.

Easa, S. M. (1994). Design considerations for highway reverse curves. Transportation Research Record, (1445).

Garber, N. J., \& Hoel, L. A. (2014). Traffic and highway engineering. Cengage Learning.

Generalna Dyrekcja Dróg Publicznych (1995a). Wytyczne projektowania dróg I i II klasy technicznej (autostrady i drogi ekspresowe) (in Polish)

Generalna Dyrekcja Dróg Publicznych (1995b). Wytyczne projektowania dróg III, IV i V klasy technicznej (in Polish)

Generalna Dyrekcja Dróg Publicznych (1995c). Wytyczne projektowania dróg VI i VII klasy technicznej (in Polish)

Grabowski, R. J. (1984). Gładkie przejścia krzywoliniowe w drogach kołowych i kolejowych, Zeszyty Naukowe AGH, Geodezja 82, 1-126. (in Polish)

Kobryń, A. (2011). Polynomial solutions of transition curves. Journal of Surveying Engineering, 137(3), 71-80. https://doi.org/10.1061/(ASCE)SU.1943-5428.0000044

Kobryń, A. (2016a). Universal solutions of transition curves. Journal of Surveying Engineering, 142(4), 04016010.

https://doi.org/10.1061/(ASCE)SU.1943-5428.0000179

Kobryń, A. (2016b). Vertical arcs design using polynomial transition curves. KSCE Journal of Civil Engineering, 20(1), 376-384.

https://doi.org/10.1007/s12205-015-0492-z 
Kobryń, A. (2017a). Transition curves for highway geometric design (Vol. 14). Cham, Switzerland: Springer. https://doi.org/10.1007/978-3-319-53727-6

Kobryń, A. (2017b). Use of polynomial transition curves in the design of horizontal arcs. Roads and Bridges - Drogi i Mosty, 16(1), 5-14. https://doi.org/10.7409/rabdim.017.001

Kühn, W. (2013). Fundamentals of road design (Vol. 20). WIT Press.

Lamm, R., Psarianos, B., \& Mailaender, T. (1999). Highway design and traffic safety engineering handbook. McGraw-Hill.

Ministra Transportu i Gospodarki Morskiej (MTiGM) (1999). Rozporządzenie Ministra Transportu i Gospodarki Morskiej w sprawie warunków technicznych, jakim powinny odpowiadać drogi publiczne I ich usytuowanie (Dz.U. nr 43, poz.430) (in Polish)

Rogers, M., \& Enright, B. (2016). Highway engineering, John Wiley \& Sons Inc.

Shebl, S. A. (2015). Single reverse and unsymmetrical vertical curve for highways utilizing quintic polynomial equation of odd powers. Journal of Applied Computational Mathematics, 5(4), 1-7.

https://doi.org/10.4172/2168-9679.1000257

Wolhuter, K. (2015). Geometric design of roads handbook. CRC Press.
S-Shaped Transition Curves as an Element of Reverse Curves in Road Design 